\title{
Strength Analysis of a Steel Structure of Weights Boxes by Means of Simulation Computations
}

\author{
Miroslav Blatnický $^{1 *}$, Ján Dižo ${ }^{1}$ and Stasys Steišūnas ${ }^{2}$
}

${ }^{1}$ University of Žilina, Department of Transport and Handling Machines, Univerzitná 8215/1, Žilina, Slovak Republic; Email: miroslav.blatnicky@fstroj.uniza.sk, jan.dizo@fstroj.uniza.sk

${ }^{2}$ Vilnius Gediminas University of Technology, Department of Railway Transport, J. Basanavičiaus g. 28, Vilnius, Lithuania; Email: stasys.stesunas@vgtu.lt

\section{*Corresponding Author: Miroslav Blatnický}

\begin{abstract}
In this article the strength analyses of weights boxes are presented. Boxes are designed as a welded steel structure at which weights with total mass almost ten tons are stored in them. These boxes are an integral part of a mechanism intended for calibration of the mass measurement device. The article contains on one hand the basic scope of the theory of elasticity and strength analysis and on the other hand the numerical computations of the structure by using the Finite Element Method. Based on results the structure of weights boxes was modified in order to satisfy the defined safety factor.
\end{abstract}

Keywords: weights boxes, strength analyses, Finite element method, numerical computations.

\section{Introduction}

As all devices for measuring physical quantities also the scales have to be regularly calibrated. For this process we need to use an adequate equipment to ensure the required accuracy. Presented boxes are an integral part of such equipment - mechanism, which will be used for verification and calibration of the scales. The whole mechanism is designed to be able to calibrate scales up to ten tons. Since this mechanism will be lifted, the boxes structure has to be designed to meet strength requirements throughout its lifetime. Therefore, strength analysis is an inherent step in the design of boxes structure.

The calibrating mechanism has total six weights boxes, which are placed above each other. In every box four weights are stocked. During the calibrating process weights boxes are gradually lifted by the hydraulic cylinder. Figure 1 shows the structure of weights boxes. 

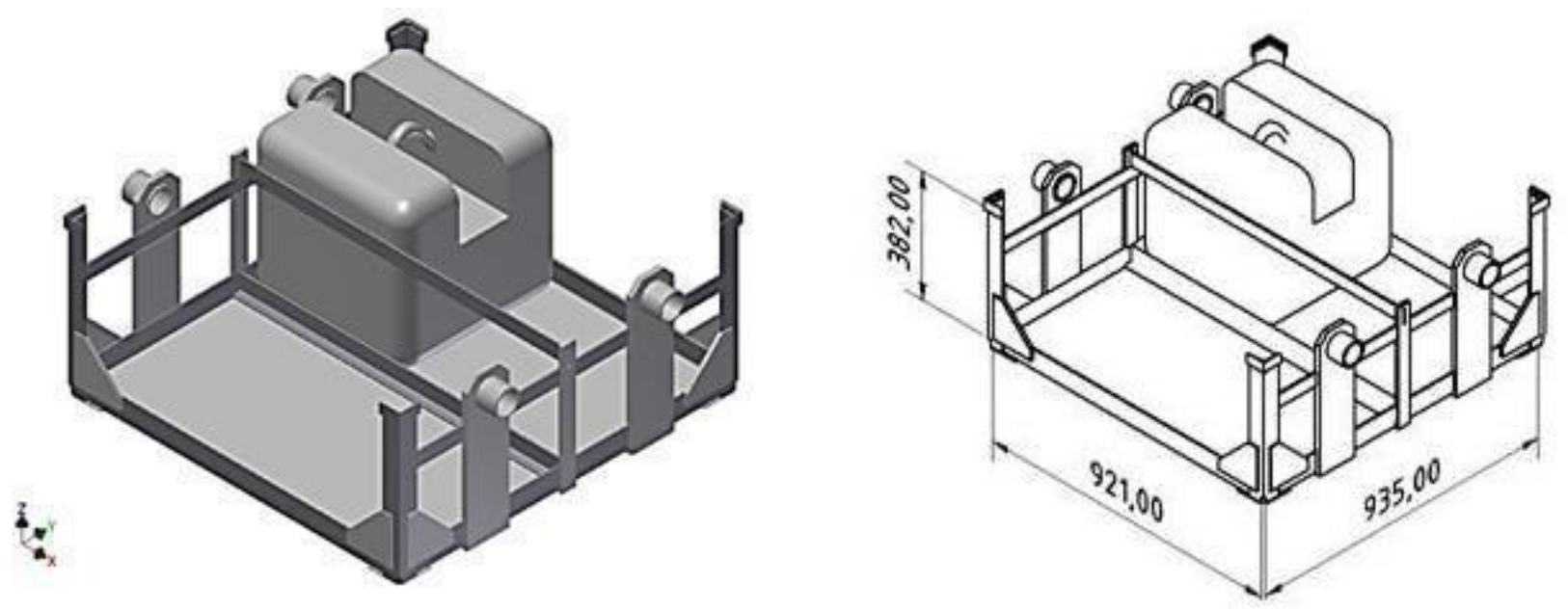

Fig. 1 Three-dimensional computer model of the one weights box (left) with a view of its main dimensions (right). Source: [authors]

\section{Strength Analysis of the Structure}

The main load of boxes is generated by gravitational forces of individual weight and own weight of boxes. As dominant stresses we considered bending, compression, shear and their effects on the boxes structure we checked by means of simulation computations. Before analysing it is necessary to determine the comparative criterion, based on which we will able to evaluate the results from numerical calculations.

For the designed structure the material steel 11523 was chosen. The yield stress of this material is $R_{e}=320-360 \mathrm{MPa}$ and the ultimate stress is $R_{m}=520-640 \mathrm{MPa}$ [1]. The safety factor is $k=2[-]$. In locations of welds it is necessary assume that the ultimate stress will be decreased of $30 \%$. The welding factor is $c=0.7[-]$.

The ultimate stress $\sigma_{P}$ with the considered safety factor is:

$$
\sigma_{P}=\frac{R_{Y}}{c_{S}}=\frac{320}{2}=160 \mathrm{MPa}
$$

and the ultimate stress in welds $\sigma_{P W}$ is:

$$
\sigma_{P W}=c_{W} \cdot \sigma_{P}=0.7 \cdot 160=112 M P a,
$$

Now, we can proceed to the numerical analysing the structure. This composes any specifics. There are described below.

As a first step, we created the box geometry by means of CAD software and this model was imported as a shell structure into the PreProcessor of Adina software [2-4]. Then, we defined general settings of the FE program, such as the time function, material properties and boundary 
conditions [5-8]. For this calculation, it was chosen one time step of the one number of steps. Material properties correspond to the material described above.

Weights boxes had to be analysed in term of strength for several cases, because it was not certainly possible to determine in advance, which one would be the worst.

The $1^{\text {st }}$ adverse case occurs for the bottommost box, when the device is fully loaded and the total weight of eight tons acts on the top of "L" profiles. The bottom of the box is also loaded by weight of two tons (of its own weight) indeed, but this fact may not to be taken into account, since the box lies on the ground; this also defines the fixity.

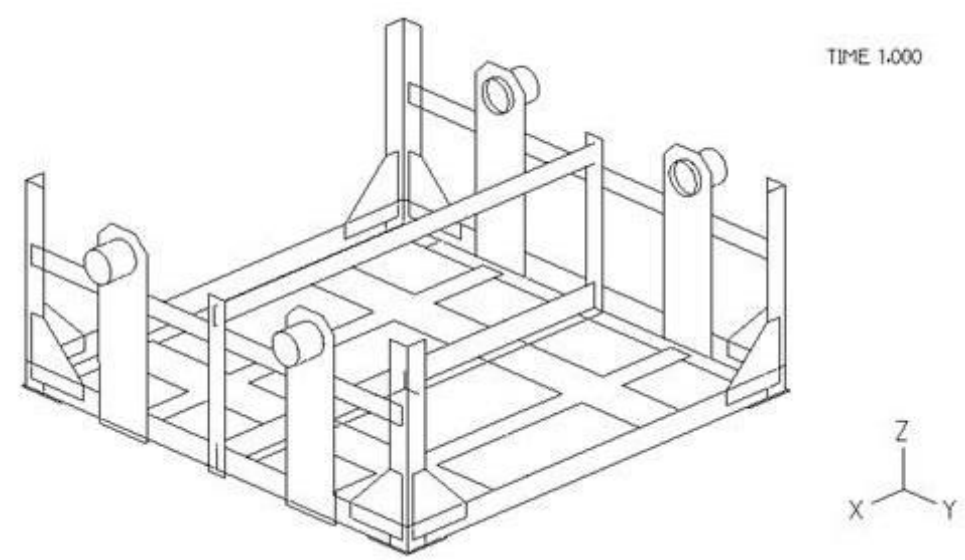

Fig. 2 Shell model of the box structure. Source: [authors]

The specification of boundary conditions is the indispensable next step. The boundary conditions were defined in four corners so that the operating conditions would be correctly simulated. This was followed by the "element group" assigning individual bodies of the structure. The element type was prescribed the same for all bodies - shell element type (Fig. 2), but the thickness was for individual parts different. In this simulation there were used nine various thicknesses - 3, 5, 6, 8, 9, 10, 11, 15 and $17 \mathrm{~mm}$.

Detail of boundary conditions for one corner of the box is shown in Fig. 3.
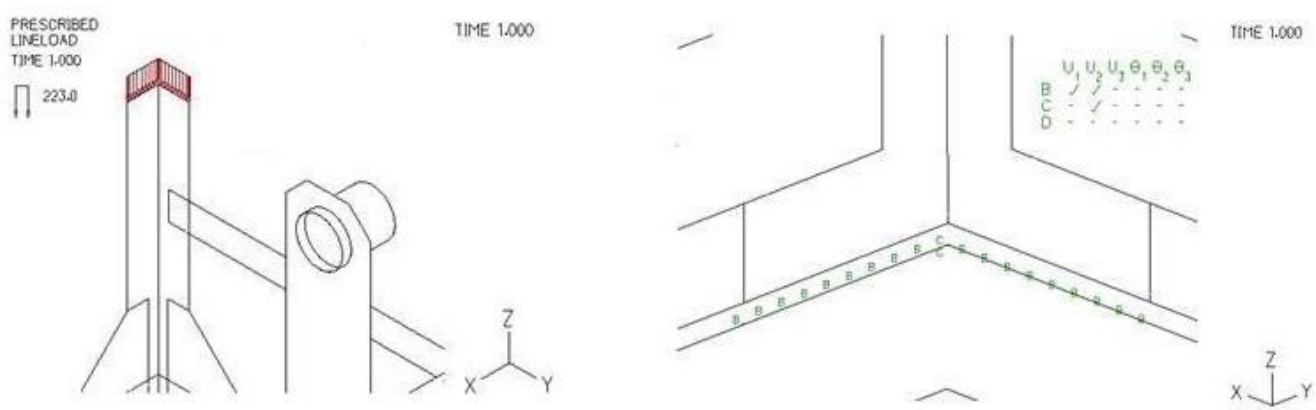

Fig. 3 Shell model of the box structure. Source: [authors]

In the FE model, the load $q_{1}$ was applied on all four "L" profiles through the line distributed load (Fig. 6 left), which value was calculated as follow: 


$$
q_{1}=\frac{F_{1}}{l}=\frac{m_{1} \cdot g}{l}=\frac{8,000 \cdot 9.81}{8 \cdot 44}=223 N \cdot \mathrm{mm}^{-1}
$$

where $g\left(m . s^{-2}\right)$ is the gravitational acceleration and denominator of the equation (3) represents eight lines with the same length of $44 \mathrm{~mm}(l=44 \mathrm{~mm})$, which are under the burden with the total weight of $8,000 \mathrm{~kg}\left(m_{l}=8,000 \mathrm{~kg}\right)$.

There are real thicknesses of sheet parts of the box. For the calculation accuracy there are important correct option for the mesh density, mesh algorithm and type of elements. We chose mesh density of $5 \mathrm{~mm}$ and the Advancing Front with linear tetrahedrons mesh algorithm. After model meshing (Fig. 4 left) we launched calculation. After its successful running we checked analysis results in PostProcessor modulus of Adina software [9-12].

Let's have a look at Fig. 4 right. We can see, the maximum reduced stress of the box according to the HMH hypothesis is indicated in the location 2 and it reached the value of 57.14 MPa. This stress value is sufficient margin below the permissible stress of $120 \mathrm{MPa}$ and this designed structure is able to carry loads safely for the $1^{\text {st }}$ case load.
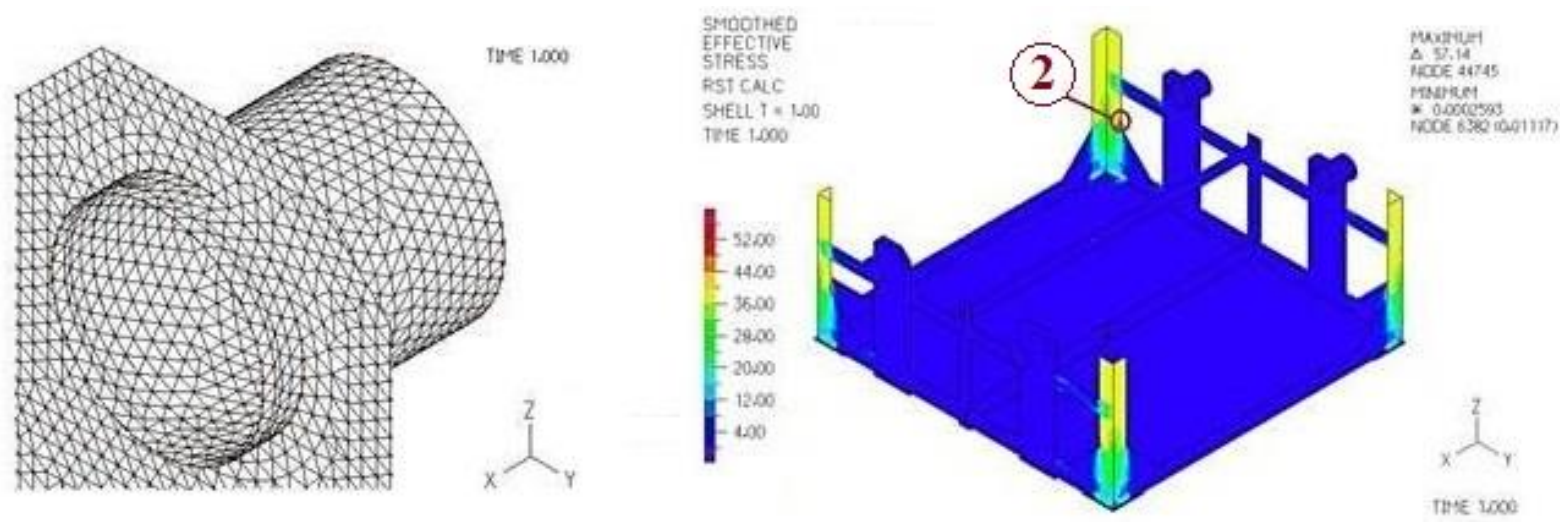

Fig. 4 Detail of used mesh (left) and distribution of HMH reduced stress in the $1^{\text {st }}$ load case (right).

Source: [authors]

The $2^{\text {nd }}$ adverse case happens, if we consider the second box from the bottom. As previously, the geometry of this box was the same, but the load was different. Whereas in the previous case the load only acted in one direction, this box was also loaded by weights, which are placed in it. In such a way, six tons load the top of "L" profiles and the bottom of the box is subjected to load of two tons. This situation is shown in Fig. 5. 


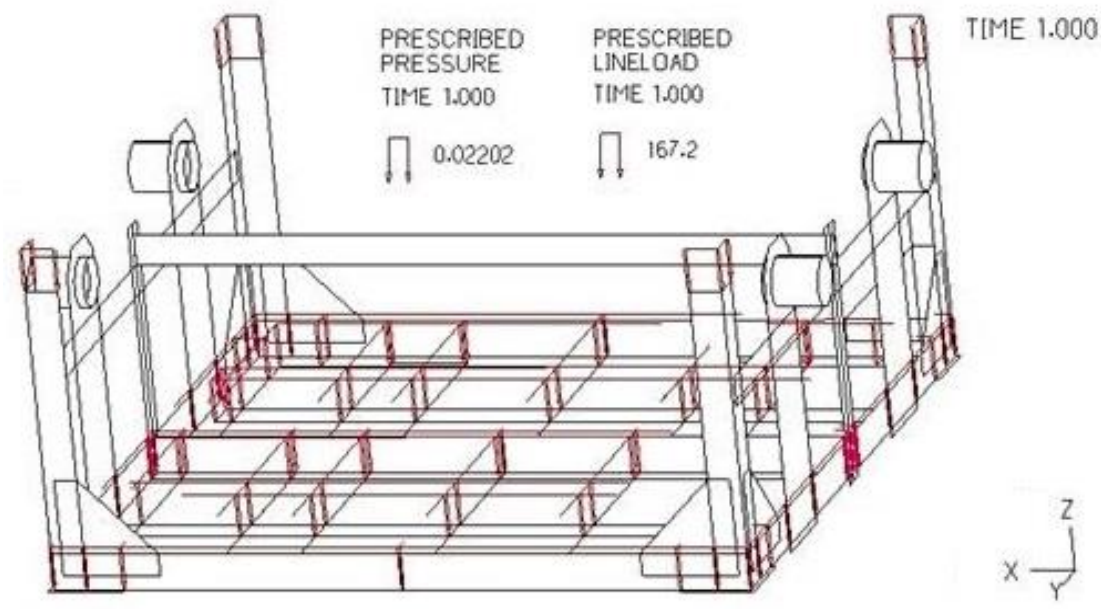

Fig. 5 Load of the box in the $2^{\text {nd }}$ loading case. Source: [authors]

Since this box does not lie on the ground (as in the $1^{\text {st }}$ one), we could not this load neglected. The correspondent load was defined on the top of "L" profiles through the line distributed load $q_{2}$, which value was calculated according to the equation (4):

$$
q_{2}=\frac{F_{2}}{l}=\frac{m_{2} \cdot g}{l}=\frac{6,000 \cdot 9.81}{8 \cdot 44}=167.2 N \cdot \mathrm{mm}^{-1},
$$

where $m_{2}(\mathrm{~kg})$ is mass of the structure for the $2^{\text {nd }}$ load case. After task solution we can show reduced stress (Fig. 6).

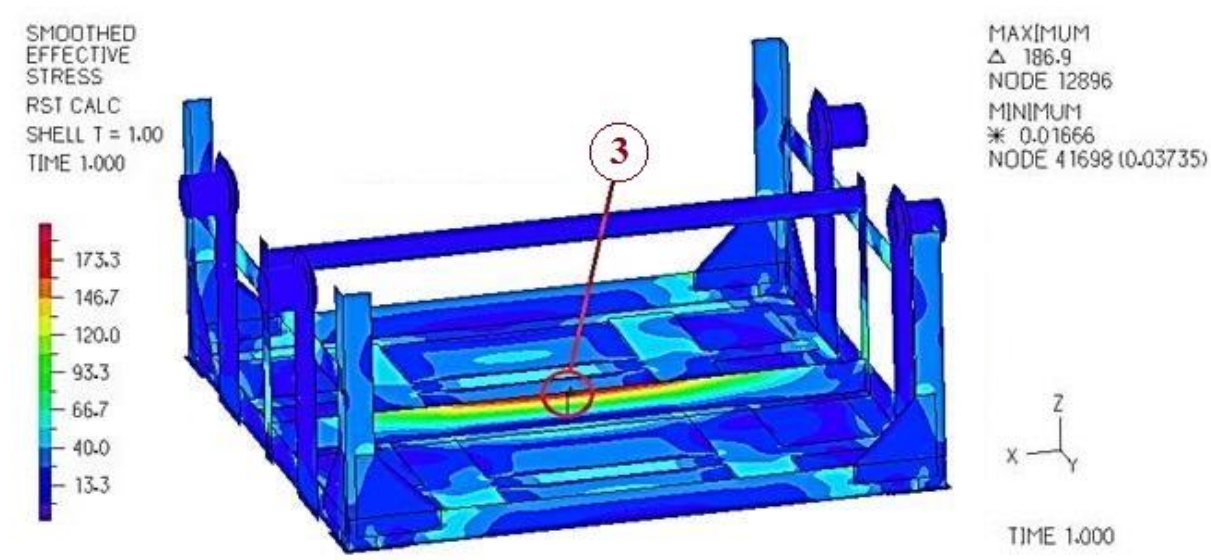

Fig. 6 Reduced HMH stress in the $2^{\text {nd }}$ loading case. Source: [authors]

As we can see in Fig. 6, the highest value of reduced stress was found in the location 3 and it reached values of $186.9 \mathrm{MPa}$. Now if we compare values of calculated stresses with the ultimate stress (eq. 1), the stress value of $186.9 \mathrm{MPa}$ was inadmissible, as well as stresses values in welds exceeded the maximum ultimate stress (compare with eq. 2). Therefore the optimization of the analysed structure was performed.

Finally, the $3^{\text {rd }}$ worst case happens when the structure is lifted by the hydraulic cylinder. We considered any of four larger boxes. Compared with previous cases, analyses, calculations, 
boundary conditions and load were changed. These boxes hang in the sidewall thus whole weight is transmitted by sidewalls and they no longer act on each other. Boxes are loaded only by weights placed in them. This load was applied as in the $2^{\text {nd }}$ case through the pressure (weights are the same). Then we specified boundary conditions again. The detail of this is shown in Fig. 7 left.

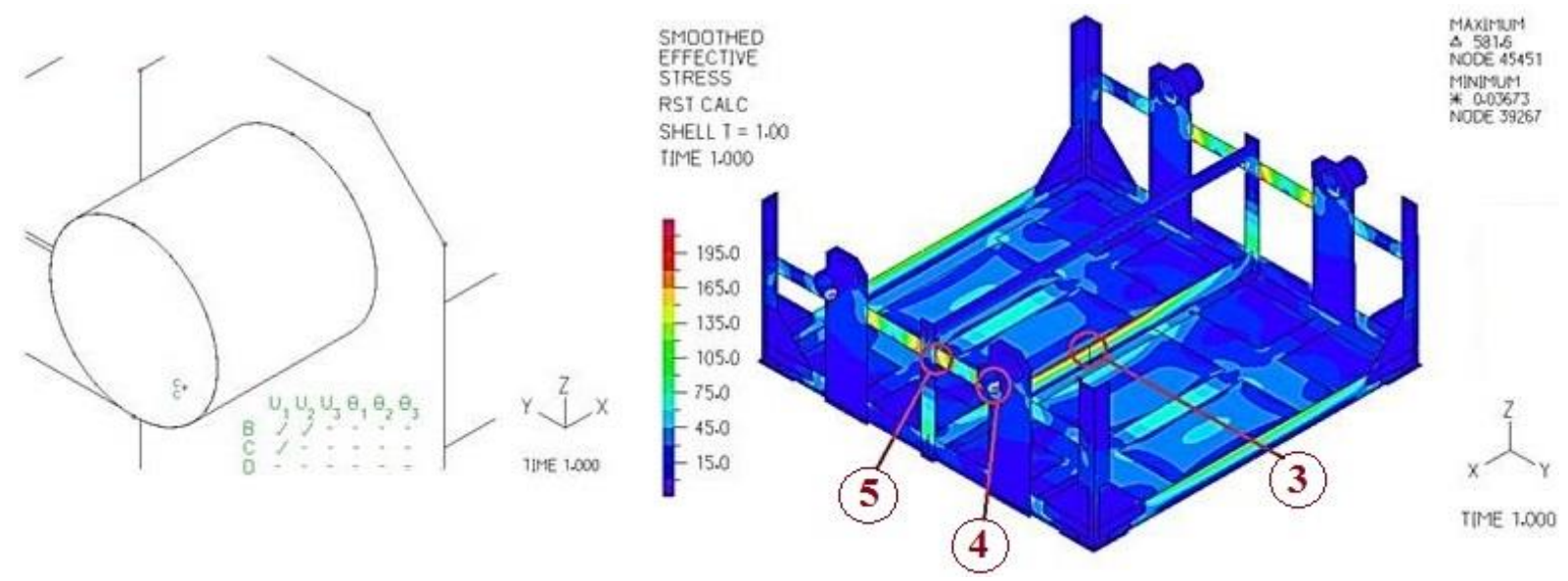

Fig. 7 Boundary conditions (left) and reduced HMH stress in the $3^{\text {rd }}$ loading case. Source: [authors]

Results from stress analysis in the $3^{\text {rd }}$ load case are shown in Fig. 7 right. We can see the highest stress of 581.6 $\mathrm{MPa}$ was in the location 4. It is not fair value but only locally increased stress because point attachment. Therefore we do no longer consider this value. In the location 5 the stress of $175 \mathrm{MPa}$ was detected. In the location 3 the highest stress was slightly higher than in the $2^{\text {nd }}$ load case and that is the stress of $200 \mathrm{MPa}$.

\section{Modification and Reanalysing Weights Boxes Structure}

As we have found out, analysed parts of the device structure are not able to transmit the required load. Thus it is necessary to perform a modification of the device design in locations 3,4 and 5 (Fig. 7 right) and also in location 2 (Fig. 4 right). After considering several aspects the thickness of profiles was changed in locations 3 and 4 from the original $5 \mathrm{~mm}$ to $10 \mathrm{~mm}$ and in the location 6 form $5 \mathrm{~mm}$ to $15 \mathrm{~mm}$. In the location 2 the bending stress $\sigma_{B}(M P a)$ is the dominant stress component and we modified the structure based on this known equation (5):

$$
\sigma_{B}=\frac{M_{B}}{W_{B}},
$$

where $M_{B}(\mathrm{Nm})$ is the bending moment and $W_{B}\left(\mathrm{~mm}^{3}\right)$ is the section bending modulus of the stiffener and for a rectangular cross-section is given by the formula (6):

$$
W_{B}=\frac{b \cdot h^{2}}{6}
$$


where $b(\mathrm{~mm})$ and $h(\mathrm{~mm})$ are dimension of the considered rectangular while square is the dimension which is parallel with the acting force direction.

From equations 5 and 6 we can express and calculate the acting bending moment $M_{B}$ :

$$
M_{B}=\frac{\sigma_{B} \cdot b \cdot h^{2}}{6}=\frac{200 \cdot 6 \cdot 50^{2}}{6}=5.10^{5} \mathrm{~N} \cdot \mathrm{mm}
$$

Hence the maximum bending moment for the original height of stiffener is $M_{B}=5.10^{5} \mathrm{~N} . \mathrm{mm}$. For the height modification of the stiffener we consider the lower value of the bending and that $\sigma_{B \bmod }=100 M P a$. Then we can calculate the modified value of the stiffener height:

$$
h_{\mathrm{mod}}=\sqrt{\frac{6 \cdot M_{B}}{b \cdot \sigma_{B \text { mod }}}}=\sqrt{\frac{6 \cdot 5 \cdot 10^{5}}{6 \cdot 100}}=70.711 \mathrm{~mm},
$$

Therefore, the profile height was approximated and changed to $h_{m o d}=70 \mathrm{~mm}$.

Results show, that after design modification stresses in locations 3 and 4 reached value up to 65 $\mathrm{MPa}$ (Fig. 8), stress values in locations 2 and 6 were of $105 \mathrm{MPa}$ and $80 \mathrm{MPa}$ respectively. Even now designed cross-sections correspond to considered loads.

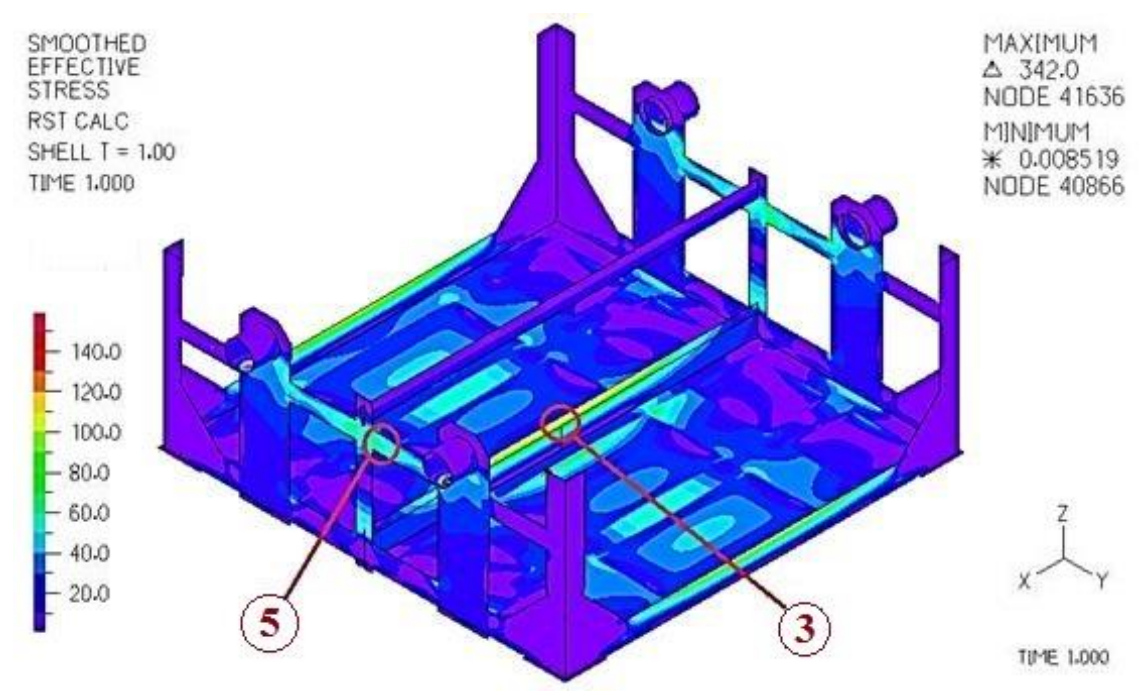

Fig. 8 Reduced HMH stress for the $3^{\text {rd }}$ loading case after modification of the box structure. Source: [authors]

\section{Conclusion}

The article deals with the strength analysis of selected parts of the calibrating mechanism - weights boxes. Based on the structure's draft model created in CAD software we prepared FE model. Subsequently, we performed strength analyses of the steel structure of boxes and we found out that original designed structure was not able to withstand the required loading. Hence we performed the 
design modification of the structure in most exposed locations. Then we performed reanalyses and comparison results with ultimate stresses. The modified structure already fulfilled the safety requirements load factor. Findings prove how important there are links between stages of a product life cycle.

\section{Acknowledgments}

The work was supported by the Cultural and Educational Grant Agency of the Ministry of Education of the Slovak Republic in project No. KEGA 077ŽU-4/2017: Modernization of the Vehicles and engines study program.

\section{References}

[1] Bajla, J., Broncek, J., Antala, J \& Sekeresova, D. (2014). Mechanical Engineering Tables (In Slovak). Selection standard. Slovak Office Standards, Metrology and Testing. ISBN 978-808130-039-4.

[2] Klimenda, F., Soukup, J. \& Zmindak, M. (2016). Deformation of aluminium thin plate. Manufacturing Technology, 16(1), 124-129.

[3] Stefanovych, T., Shcherbovskykh, S. \& Drozdzdiel, P. (2016). The reliability model for failure cause analysis of pressure vessel protective fittings with taking into account load-shearing effect between valves. Diagnostyka, 16(4), 17-24.

[4] Stastniak, P., Gerlici, J., Lack, T. \& Harusinec, J. (2013). Computer aided simulation analysis for computation of modal analysis of the freight wagon. In: TRANSCOM 2013: 10th European conference of young researchers and scientists: Žilina, June 24-26, 2013, (pp. 297-300). Slovak Republic. Žilina, University of Žilina.

[5] Bogdevicius, M., Zygiene, R., Bureika, G. \& Dailydka, S. (2016). An analytical mathematical method for calculation of the dynamic wheel-rail impact force caused by wheel flat. Vehicle System Dynamics, 54(5), 689-705.

[6] Loulova, M., Suchanek, A. \& Harusinec, J. (2017). Evaluation of the parameters affecting passenger riding comfort of a rail vehicle. Manufacturing Technology, 17(2), 224-231.

[7] Hauser, V., Nozhenko, O. S., Kravchenko, K. O., Loulova, M., Gerlici, J. \& Lack, T. (2016). Influence of axles steering and geometry of wheel profile on the vehicle behaviour in rail track curving. In Dynamics of rigid and deformable bodies 2016 (electronic source): Proceedings of international scientific conference, Ústi nad Labem, Czech Republic, 5 - 7 October 2016 (8 pages). Ústí nad Labem, Czech Republic. 
[8] Benca, S. (2006). Calculation procedures of the Finite Element Method for linear tasks solving of mechanics. (In Slovak). Slovak University of Technology in Bratislava, Bratislava.

[9] Lack, T., Gerlici, J. \& Manurova, M. (2016). Freight car bogie properties analysis by means of simulation computations. Manufacturing Technology, 16(4), 667-672.

[10] Gerlici, J. \& Lack, T. (2014). Rail vehicles brake components test bench utilisation. Applied mechanics and materials, 486, pp. 379-386.

[11] Gerlici, J. \& Lack, T. (2011). Railway wheel and rail head profiles development based on the geometric characteristics shapes. Wear, 271(1-2), 246-258.

[12] Gerlici, J., Lack, T. \& Harusinec, J. (2014). Realistic simulation of railway operation on the RAILBCOT test stand. Applied mechanics and materials, 486, 387-395. 